\title{
Lead adsorption on carbon nanotubes
}

\author{
Yan-Hui Li ${ }^{\text {a,* }}$, Shuguang Wang ${ }^{\text {b }}$, Jinquan Wei ${ }^{\text {a }}$, Xianfeng Zhang ${ }^{\text {a }}$, Cailu Xu ${ }^{\text {a }}$, \\ Zhaokun Luan ${ }^{\mathrm{b}}$, Dehai Wu ${ }^{\mathrm{a}}$, Bingqing Wei ${ }^{\mathrm{c}}$ \\ a Department of Mechanical Engineering, State Key Laboratory of Automotive Safety and Energy, Tsinghua University, \\ Beijing 100084, China \\ b State Key Laboratory of Environmental Aquatic Chemistry, Research Center for Eco-Environmental Sciences, \\ Chinese Academy of Sciences, Beijing 100085, China \\ c Department of Materials Science and Engineering, Rensselaer Polytechnic Institute, Troy, NY 12180, USA
}

Received 8 February 2002; in final form 19 March 2002

\begin{abstract}
Carbon nanotubes (CTNs) show exceptional adsorption capability and high adsorption efficiency for lead removal from water. The adsorption is significantly influenced by the $\mathrm{pH}$ value of the solution and the nanotube surface status, which can be controlled by their treatment processing. The adsorption isotherms are well described by both Langmuir and Freundlich models. Our results suggest that CNTs can be good $\mathrm{Pb}^{2+}$ adsorbers and have great potential applications in environmental protection. (c) 2002 Elsevier Science B.V. All rights reserved.
\end{abstract}

\section{Introduction}

The effects of heavy metals such as lead, mercury, copper, zinc and cadmium on human health have been studied extensively. Excessive ingestion of them can causes accumulative poisoning, cancer, nervous system damage, etc [1,2]. Lead is ubiquitous in the environment and is hazardous at high levels. It is a general metabolic poison and enzyme inhibitor [3] and can accumulate in bones, brain, kidney and muscles. Long-term drinking water containing high level of lead can cause se-

\footnotetext{
${ }^{*}$ Corresponding author. Fax: +10-6278-2413. Li).
}

rious disorders, such as anaemia, kidney disease and mental retardation.

Lead in wastewater comes mainly from battery manufacturing, printing, painting, dying and other industries. Unlike organic compounds, lead is nonbiodegradable and, therefore, must be removed from water [4]. Various methods of lead removal from wastewater have been developed and adsorption with activated carbon is a common used method. Increasingly stringent standard on the quality of drinking water has stimulated a growing effort on the exploiture of new high efficient adsorbents.

Carbon nanotubes (CNTs), a new form of carbon, are attracting researchers' great interest due to their exceptional mechanical properties [5] and unique electrical property [6], highly chemical 
stability and large specific surface area since their discovery [7]. Their hollow and layered nanosized structures make them a good candidate as adsorbers. Long et al. [8] reported that CNTs had a significantly higher dioxin removal efficiency than that of activated carbon. Our previous studies showed that CNTs are good fluoride adsorbers and their fluoride removal capability is superior to activated carbon [9]. In this Letter, we report that CNTs have high lead adsorption capacity and can be used as an adsorbent for lead removal from water.

\section{Experimental}

CNTs (Fig. 1) were fabricated by catalytic pyrolysis of the propylene-hydrogen $\left(\mathrm{C}_{3} \mathrm{H}_{6}: \mathrm{H}_{2}=\right.$ $2: 1)$ mixture at $750{ }^{\circ} \mathrm{C}$ in a ceramic tube furnace using Ni particles as catalysts. The as-grown CNTs were dispersed in concentrated nitric acid and refluxed at $140{ }^{\circ} \mathrm{C}$ for $1 \mathrm{~h}$ to remove most of the catalyst particles. Lead stock solution $(1000 \mathrm{mg} / \mathrm{l})$ was prepared by dissolving lead nitrate in deionized water. The solution was further diluted to the required concentrations before used.

Batch sorption isotherms were carried out in glass tubes at room temperature. Weighed amounts $(0.05 \mathrm{~g})$ of the as-grown CNTs and the acid-refluxed CNTs were introduced into tubes, respectively, to which $100 \mathrm{ml}$ of lead solution of increased initial concentrations $\left(C_{0}\right)$ from 2 to 14

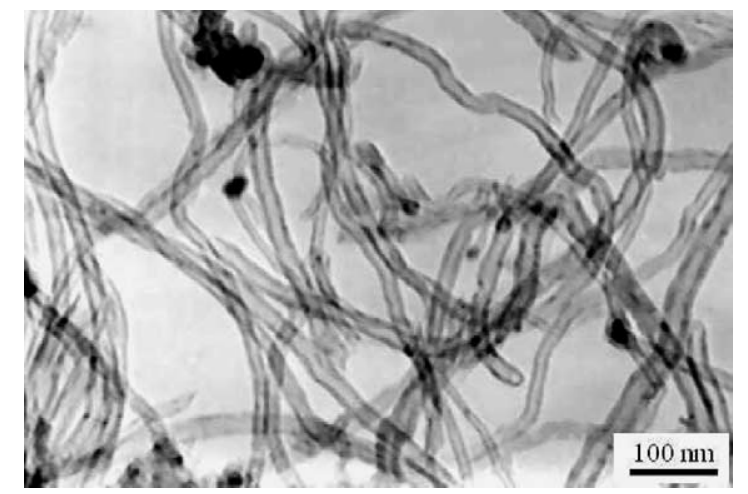

Fig. 1. TEM image of as-grown carbon nanotubes. The average diameter is about $\sim 30 \mathrm{~nm}$ and the length ranges from hundreds of nanometers to micrometers. $\mathrm{mg} / \mathrm{l}$ with an interval of $2 \mathrm{mg} / \mathrm{l}$ were added. The $\mathrm{pH}$ value of the solution at 3.0, 5.0 and 7.0 were chosen to study the $\mathrm{pH}$ value effect on lead removal. The glass tubes were mounted on a shaker (HZQ-C) and shaken for $6 \mathrm{~h}$ at room temperature, then the suspension was filtered through $0.45 \mu \mathrm{m}$ membrane filters. The filtrates were immediately measured by an atomic adsorption spectrometer. The amount of $\mathrm{Pb}^{2+}$ adsorbed on CNTs was determined by the $\mathrm{Pb}^{2+}$ difference between the initial $\mathrm{Pb}^{2+}$ concentration and the equilibrium $\mathrm{Pb}^{2+}$ concentration.

\section{Results and discussion}

The treatment processing has great impact on the CNTs adsorption capability for $\mathrm{Pb}^{2+}$ removal as demonstrated in Fig. 2. Fig. 2a shows that the as-grown CNTs have weak adsorption capability of $\mathrm{Pb}^{2+}$ and reach the largest adsorption capacity of $1 \mathrm{mg} / \mathrm{g}$ as the equilibrium $\mathrm{Pb}^{2+}$ concentration increases to $7.5 \mathrm{mg} / \mathrm{l}$. The adsorption capacity increases remarkably when the CNTs were refluxed with concentrated nitric acid at $140{ }^{\circ} \mathrm{C}$ for $1 \mathrm{~h}$. The adsorption capacity of $15.6 \mathrm{mg} / \mathrm{g}$ is obtained for the treated CNTs at $\mathrm{Pb}^{2+}$ equilibrium concentration of $2.7 \mathrm{mg} / \mathrm{l}$ (Fig. 2b). It is already known that the adsorption capability of activated carbon is mainly determined by the functional groups introduced by oxidation [10]. Oxidation of CNTs with oxidized acid can also introduce many func-

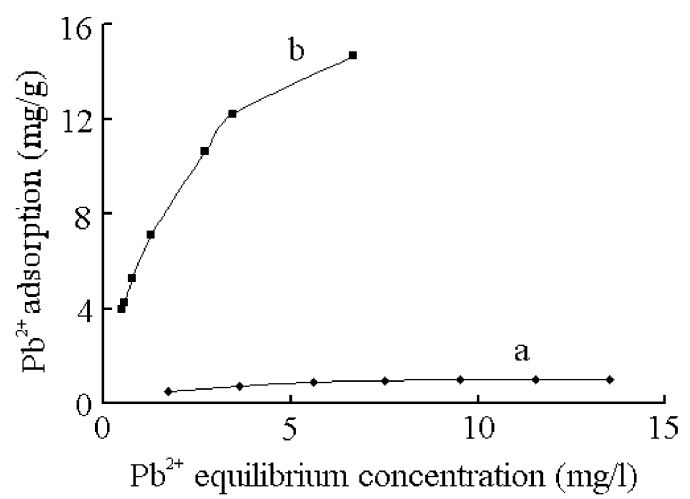

Fig. 2. Adsorption isotherms of $\mathrm{Pb}^{2+}$ onto CNTs. (a) the asgrown CNTs; (b) the acid-refluxed CNTs $(\mathrm{pH}=5.0)$. 
tional groups, such as hydroxyl $(-\mathrm{OH})$, carboxyl $(-\mathrm{COOH})$ and carbonyl $(>\mathrm{C}=\mathrm{O})$, on the surface of CNTs [11]. These functional groups attached on the surfaces of the CNTs improve their adsorption capability of $\mathrm{Pb}^{2+}$ in solution.

The removal of $\mathrm{Pb}^{2+}$ from water by acid-refluxed CNTs was found to be highly dependent on the solution $\mathrm{pH}$ value, which affects the surface charge of the adsorbent and degree of ionization and speciation of the adsorbates. Fig. 3 shows that the $\mathrm{Pb}^{2+}$ adsorption capacity of the CNT increases with the $\mathrm{pH}$ value from 3.0 to 7.0. Precipitation will occur between $\mathrm{Pb}^{2+}$ and $\mathrm{OH}^{-}$as the $\mathrm{pH}$ exceeds to 7.0, so our experiments were carried out only under acidic condition. At $\mathrm{pH}=3.0$, adsorption effect is very weak due to the competition of $\mathrm{H}^{+}$with $\mathrm{Pb}^{2+}$ on the adsorption sites (Fig. 3a); at $\mathrm{pH}=5.0$, the adsorption capability increases due to role of functional groups on the CNTs surfaces (Fig. 3b); at $\mathrm{pH}=7.0$, the adsorption capacity increases remarkably (Fig. 3c). It has been reported that at $\mathrm{pH}$ between 5.5 and 11.5, the

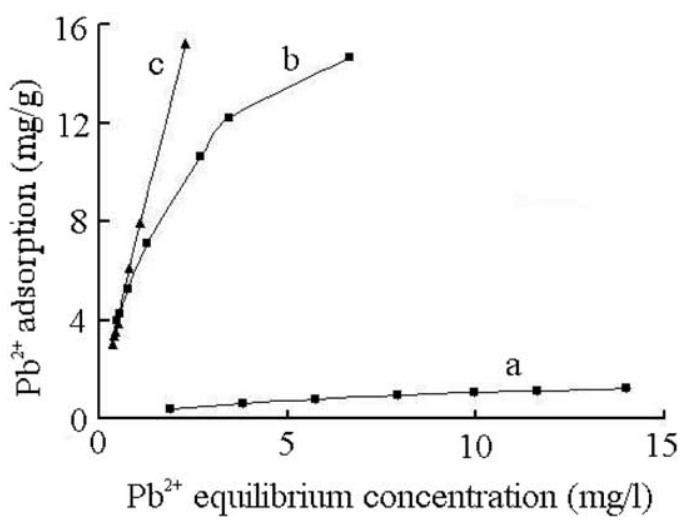

Fig. 3. Adsorption isotherms of $\mathrm{Pb}^{2+}$ removal by acid-refluxed CNTs at different $\mathrm{pH}$ values. (a) $\mathrm{pH}=3.0$; (b) $\mathrm{pH}=5.0$; (c) $\mathrm{pH}=7.0$. adsorption of lead by activated carbon was interfered by the precipitation of white gelatinous plumbous hydroxide [12]. The higher adsorption capacity of CNTs at $\mathrm{pH}=7.0$ may be also the cooperating role of adsorption and precipitation.

The experimental data for $\mathrm{Pb}^{2+}$ adsorption on acid-refluxed CNTs at different $\mathrm{pH}$ values could be approximated by the isotherm models of Langmuir (1) and Freundlich (2),

$q=\frac{q_{\mathrm{m}} K_{\mathrm{L}} C}{1+K_{\mathrm{L}} C}$,

where $C$ is the equilibrium lead concentration $(\mathrm{mg} /$ $1), q$ is the amount adsorbed $(\mathrm{mg} / \mathrm{g})$ and $q_{\mathrm{m}}$ and $K_{\mathrm{L}}$ are Langmuir constants related to adsorption capacity and energy of adsorption, respectively.

$q=K_{\mathrm{F}} C^{1 / n}$,

where $K_{\mathrm{F}}$ and $n$ are Freundlich constants related to adsorption capacity and adsorption intensity, respectively.

It can be seen from Table 1 that both Langmuir and Freundlich models show good agreement with the experimental data, with the correlation coefficient values of $0.9945-0.9953$ and $0.9877-0.9974$ at different $\mathrm{pH}$ values. The parameters $q_{\mathrm{m}}$ and $K_{\mathrm{F}}$, which are related to the adsorption capacity, increase with $\mathrm{pH}$ values. This is consistent with the experimental observation.

Time course of $\mathrm{Pb}^{2+}$ adsorption onto the acidrefluxed CNTs was conducted using a lead solution of $10 \mathrm{mg} / \mathrm{l}$ concentration (Fig. 4). The amount of $\mathrm{Pb}^{2+}$ adsorbed onto the acid-refluxed CNTs increased rapidly during the beginning $8 \mathrm{~min}$ (16.4 $\mathrm{mg} / \mathrm{g}$ adsorbent, $81.6 \%$ removal). Subsequently, the adsorption rate rises gradually and reaches equilibrium after $40 \mathrm{~min}$ for $\mathrm{Pb}^{2+}$ adsorption to reach equilibrium $(17.5 \mathrm{mg} / \mathrm{g}, 87.8 \%$ removal). The short time needed to reach equilibrium suggests that the CNTs have very high adsorption efficiency

Table 1

Parameters of Langmuir and Freundlich adsorption isotherm models for $\mathrm{Pb}^{2+}$ onto CNTs

\begin{tabular}{|c|c|c|c|c|c|c|}
\hline \multirow[t]{2}{*}{$\mathrm{pH}$} & \multicolumn{3}{|c|}{ Langmuir } & \multicolumn{3}{|c|}{ Freundlich } \\
\hline & $q_{\mathrm{m}}$ & $K_{\mathrm{L}}$ & $r^{2}$ & $n$ & $K_{\mathrm{F}}$ & $r^{2}$ \\
\hline 3.0 & 1.66 & 0.1648 & 0.9953 & 1.80 & 0.3184 & 0.9945 \\
\hline 5.0 & 17.44 & 0.5869 & 0.9953 & 1.91 & 5.9918 & 0.9877 \\
\hline 7.0 & 49.95 & 0.1855 & 0.9945 & 1.09 & 7.7179 & 0.9974 \\
\hline
\end{tabular}




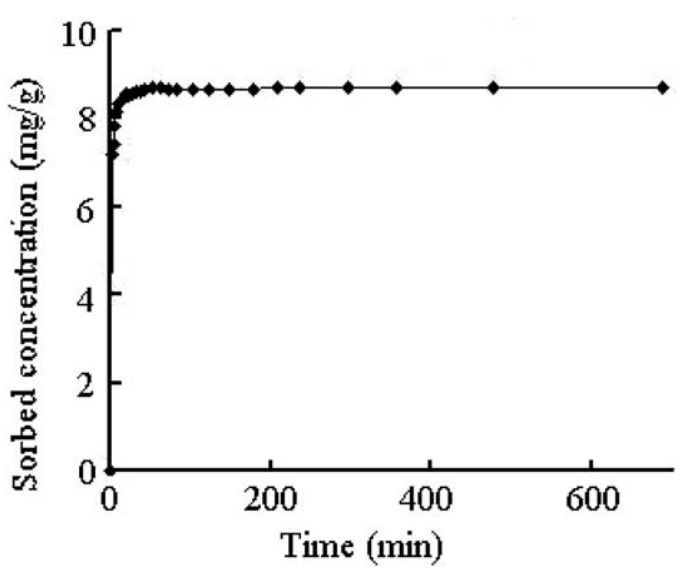

Fig. 4. Plot of the amount of $\mathrm{Pb}^{2+}$ sorbed by acid-refluxed CNTs vs time at the $\mathrm{pH}$ value of 5.0 and at room temperature.

and have a great potential in $\mathrm{Pb}^{2+}$ adsorbent application.

The $\mathrm{Pb}^{2+}$ adsorption on the CNTs depends on many factors such as the surface functional groups, the specific surface area and the solution components. The most important factor is the surface functional groups, which can be generated with oxidized acids. It is well known that oxidation treatment by nitric acid can cause an increase in the cation-exchange capacity and a decrease in the anion-exchange capacity of carbon [10]. Different functional groups with acidic nature introduced on the CNTs surfaces can dissociate at different $\mathrm{pH}$ values. Conjugation of the functional groups on oxidized CNTs surfaces causes the dissociation increase of some groups to such a degree that ion exchange is also possible in a strongly acidic medium $(\mathrm{pH}=3.0)$. Therefore, the CNTs could have good $\mathrm{Pb}^{2+}$ adsorption capacity at acid condition $(\mathrm{pH}=5.0)$. With the increase of $\mathrm{pH}, \mathrm{OH}^{-}$ions in solution increase gradually and the effects of adsorption and precipitation make adsorption capacity increase significantly. In addition, the specific surface area changes from 134 to $145 \mathrm{~m}^{3} / \mathrm{g}$ after oxidized by nitric acid. The surface area increase also benefits to the $\mathrm{Pb}^{2+}$ adsorption, but it only plays subsidiary role.

Adsorption characteristics of the heavy metals by carbon materials are much influenced by many factors, such as presence of complexing agents, $\mathrm{pH}$, valency and ionic form of the metal, adsorbate concentration and adsorbent dosage [12]. Here we only studied lead adsorption capability of quantitative CNTs $(0.05 \mathrm{~g})$ at different $\mathrm{pH}$ and found that at the same condition (lead: $\mathrm{pH}=5.1 ; C_{0}=10 \mathrm{mg}$ / 1, adsorbent: $0.05 \mathrm{~g}$ ) the adsorption capacity of acid-refluxed CNTs $(11.2 \mathrm{mg} / \mathrm{g})$ is higher than that of activated carbon (about $5.5 \mathrm{mg} / \mathrm{g}$ ) [12]. The experimental results suggest that CNTs may be an promising adsorbent for lead removal from water and detail works need to be carried out further.

\section{Conclusions}

In conclusion, CNTs show exceptional adsorption capability of $\mathrm{Pb}^{2+}$ from water after oxidized with nitric acid. The adsorption properties of CNTs depend significantly on the $\mathrm{pH}$ value of the solution. The high efficiency for $\mathrm{Pb}^{2+}$ removal by CNTs with their exceptional adsorption capability suggests that CNTs can be good $\mathrm{Pb}^{2+}$ adsorbers and have great potential applications in environmental protection.

\section{References}

[1] L. Friberg, G.F. Nordberg, B. Vouk, Handbook on the Toxicology of Metals, Elsevier, Amsterdam, 1979.

[2] J. Calderon, M.E. Navarro, M.E. Jimenez-Capdeville, M.A. Santos-Diaz, A. Golden, I. Rodriguez-Leyva, V. Borja-Aburato, F. Diaz-Brriga, Environ. Res. 85 (2001) 69.

[3] A. Denizli, E. Buyuktuncel, A. Tuncel, S. Bektas, O. Genc, Environ. Technol. 21 (2000) 609.

[4] R. Leyva Ramos, L.A. Bernal Jacome, J. Mendoza Barron, L. Fuentes Rubio, R.M. Guerrero Coronado, J. Hazard. Mater. B 90 (2002) 27.

[5] M.M. Treacy, T.W. Ebbesen, J.M. Gibson, Nature 381 (1996) 678.

[6] T.W. Ebbesen, H.J. Lezee, H. Hiura, J.W. Bennett, H.F. Ghaemi, T. Thio, Nature 382 (1996) 54.

[7] S. Iijima, Nature 354 (1991) 56.

[8] R.Q. Long, R.T. Yang, J. Am. Chem. Soc. 123 (2001) 2058.

[9] Y.H. Li, S. Wang, A. Cao, D. Zhao, X. Zhang, C. Xu, Z. Luan, D. Ruan, J. Liang, D. Wu, B. Wei, Chem. Phys. Lett. 350 (2001) 412.

[10] A. Dabrowski, Adsorption and its Applications in Industry and Environmental Protection, Elsevier, Amsterdam, 1999.

[11] Y.H. Li, C. Xu, B. Wei, X. Zhang, M. Zheng, D. Wu, P.M. Ajayan, Chem. Mater. 14 (2002) 483.

[12] T.C. Tan, W.K. Teo, Water Res. 21 (1987) 1183. 